\title{
Elementary Mathematics Teachers' and Coordinators' Perceptions about Teaching Problem Solving in North Lebanon Private Schools: an Exploratory Mixed Study
}

Lina Ramez Amanatallah, MA Education

Instructor, Lebanese International University, Tripoli, Lebanon Dalal Michel Moukarzel, PhD, Educational Sciences

Associate Professor, Saint-Joseph- University of Beirut, Lebanon

Doi:10.19044/esj.2018.v14n31p130 URL:http://dx.doi.org/10.19044/esj.2018.v14n31p130

\begin{abstract}
The purpose of this mixed research study was to explore how teaching problem solving is taking place at the elementary level in north Lebanon private schools, and to understand the challenges students were facing from the teachers' and coordinators' perspective. Four instruments were used: An inventory sent to 273 private schools, a teacher's questionnaire, a coordinator's interview, and class observations. Findings revealed that out of 129 Mathematics teachers who responded to the inventory, $126(97 \%)$ affirmed using active learning strategies (ALS). To examine how Mathematics teaching is taking place, five private English speaking schools were purposefully selected to participate in the study with five Mathematics coordinators and ten teachers. The results showed inconsistency between the inventory, coordinators' interviews, teachers' responses to the questionnaire, and class observations. While responses to the inventory and teachers 'questionnaires showed that at least $60 \%$ of teachers use ALS, class observations revealed that teachers did not make use of strategies that engage students in learning or in monitoring their progress and understanding. Moreover, teachers' and coordinators' responses to some questions showed that students' difficulties were due to two main reasons: language barrier and poor analytical skills. Recommendations for teachers' training on specific active learning strategies and adequate English language usage to teach mathematics were suggested.
\end{abstract}

Keywords: Active learning strategies, Problem solving, Mathematics, Elementary Cycle Two 


\section{Introduction:}

Problem solving is an activity through which an individual (or group) engage in a variety of cognitive actions that require knowledge and skills, and some of which are not routine. (Frank, 2013). Within Mathematics education, problem solving is one of the main challenges at the elementary level, especially for Cycle Two students (which includes Grades 4, 5 and 6 according to the Lebanese grades distribution), whose comments often echoed: "Mathematics problems are really difficult." "I did not know how to do it." "I can do calculation very well, but don't know how to solve word problems. For Skinner (1966): "A question for which there is at the moment no answer is a problem" (p. 225). Newell \& Simon added in 1972: "A person is confronted with a problem when he wants something and does not know immediately what series of actions he can perform to get it" (p. 72). Later in 1993, Kahney explained: "Whenever you have a goal which is blocked for whatever reason . . you have a problem." (p. 15). Therefore solving problems is a skill required throughout all daily activities.

\section{Research Problem}

Problem solving, is one of the major aspects of our daily activities, and is often considered by students as one of the most frustrating domains in Mathematics because it implies building on previous knowledge that they might not have fully acquired. To understand how students learn, one can rely on constructivism, experiential learning, and social learning theories, and benefit from the work of Vygotsky (1968), Piaget (1969), Dewey (1938), Bruner (1987), and Bandura (1999). The combination of these learning theories, according to Monk and Silman (2013), showed that educators help students understand their world by using an approach to planning and teaching that engages children in their learning; the term active learning is used to describe this process. Earlier, Dewey (1938) encouraged the use of activities that promote active learning in the classroom which address the whole child: physically, socially, emotionally as well as cognitively. This resulted, according to him, in more enduring and meaningful lessons and children who will move toward becoming lifelong learners. To address students' difficulty in problem solving rose the need to examine the teaching techniques and students' difficulties from coordinators' and teachers' perspectives.

Accordingly, the following questions were explored:

1- What are the instructional methods used in teaching problem solving in Tripoli's private schools?

2-What are the Mathematics teachers' and coordinators' perceptions about students' difficulties in problem solving in Cycle Two? 


\section{Research Significance}

Research on the use of active learning in Mathematics problem solving seems to be lacking in the Arab world in general (Affana \& Zaanin, 2001), and in Lebanon in particular especially for those using the Arabic or English language. In the Lebanese Mathematics curriculum, the general objectives emphasized students' conjecturing, reasoning, representing, and communicating Mathematically as stated in the official newspaper issue \# 26, 1997, pp. 288-289. However, a UNESCO study (2002) highlighted the absence of these objectives in the curriculum scope, sequences and detailed plans. From here came the need to dwell into the Lebanese schools to find out how teaching problem solving was taking place, and how coordinators and teachers perceived students difficulties in solving Mathematics problems. The outcomes of this study could provide a reliable feedback to improve the teaching of Mathematics in schools.

\section{Research Objectives}

The purpose of this mixed research study was to explore how teaching problem solving was taking place at the elementary level in north Lebanon private schools, and to understand the challenges students were facing from the teachers' and coordinators' perspective.

\section{Study Limitation}

The first limitation encountered in this study was the small number of teachers who responded to the inventory with respect to the number of schools in the North. The second limitation was the small number of schools using English as a means of instructions to teach Mathematics: only six schools, and one of these six schools withdrew from the study after the interview with its coordinators. Hence, results cannot be generalized.

\section{Literature Review}

According to Fisher (2002), being active means that the young child engages with experience, actively (as opposed to passively) bringing his or her existing knowledge and understanding to bear on what is currently under investigation. This is what causes children both physically and cognitively to construct their own view of the world, to personalize the experience and to apply it in ways that make sense to them as individuals (Bruner \& Haste, 1987). Mc Varish (2008) argues that ideally children choose to learn, not just because they want to please an adult or merely because it sounds fun but because they are genuinely interested in the subject matter. If children can be presented with problems that they really want to solve, but in order to do so they need to learn something new, learning will naturally follow since they will need to discover or inquire in order to reach solutions. However, for teachers, it takes time to 
organize and plan a lesson where this type of active learning is the norm. It also takes enthusiasm, knowledge of how children learn and a willingness to reflect and to change. Monk and Silman (2013) believed that clarifying the task objectives and teaching students how to monitor their own progress and understanding typify a classroom where active learning takes place. Claxton (2008), in his book "What's the point of school?" states that no learning can happen without students' engagement because this will make them aware of themselves as capable learners. He explained that "building learning power" helps children not necessarily to learn more, but to become better learners. Kolb (2014) built upon John Dewey (1938), in his book entitled "Experiential Learning", to suggest four stages in the learning cycle: "concrete experience, reflection/observation, conceptualization, and planning/predicting what actions should be taken for a required outcome" (p.145). Kolb's learning cycle refers to the process by which learning begins with a concrete experience and continues with reflection and modification as a result of experience. The implication is that the more we reflect on a task as we experience the process, the more opportunities we have to adapt and refine our actions. Moreover, there is a strong implication in recent research that learning can be improved by increasing learners' awareness of their own mental processes (Wray, 2006). Many researchers investigated the impact of teaching strategies on students' learning. Yet, few are the research conducted on the effect of active learning strategies in solving Mathematics problems in Cycle Two. This scarcity was mentioned by Al-Alloul (2012) who studied the effect of using active learning strategies on developing Mathematics solving problems skills in Gaza Palestine. The experimental study was based on a sample of 78 female students in Grade Four. She concluded that there was a significant difference at $(a \leq 0.05)$ between pre and post Mathematics solving problems scores when applying active learning strategies for the experimental group. Later, in 2015, Nancy K Schoolcraft conducted "the first formal look" at a cooperative learning strategy, designed to aid learners who struggle with academic language in Mathematics classes (p.7). The study described the experiences of six students in a geometry high school classroom over a three-month period. The results showed that alternating reflection and discussion with peers on Mathematics tasks increased students' understanding. Students' fluency with Mathematics vocabulary and variation of solutions increased; they made better use of homework time, their discourse increased during problem solving, and the teacher's views about the effectiveness of cooperative learning became more positive. Recently, Farrajallah (2017) in his experimental study in an elementary school in the Middle Governorates of Gaza Strip stated a list of benefits for using active learning strategies in teaching mathematical problem solving to Grade Five students. The researcher chose a sample of 78 fifth grade male students distributed on an experimental group (38) and a control group 
(38). The results showed significant statistical differences between the mean scores of the experimental group and their peers in the control group in the number sense skills and mathematical communication skills; these differences were in favor of the experimental group. Farrajallah assumed that ALS creates a healthy and vibrant environment, which brings joy to the mathematics study. He believed it also provides students an opportunity to ask questions, discuss and exchange ideas, give and receive assistance, explore situations, search for patterns and relationships in the collection of data and to freely formulate and choose assumptions. In his opinion, this is an opportunity to promote personal contact and understand the language of mathematics through students' discussions with each other. Hence, using different approaches to teach problem solving promotes students' interaction and triggers their critical thinking (CT) skills. This keeps students from adopting the passive attitude of learners who wait for others to give the answers (Kagan, 2001).

\section{Theoretical Framework}

Critical thinking and problem solving are inherent to the concepts of constructivism, social constructivism and pragmatism. The importance of constructivism is that people learn best when they can see the usefulness of what they learn and connect it to the real world; the work of Vygotsky (1986), Bruner (1986), and Egan (1997) emphasized these points and were taken as basis for this study. Pragmatism, which derives from the work of Pierce, James, Mead, and Dewey as cited in Cherryholmes (1992), is not committed to one system of philosophy and reality (Creswell, 2014); it gives researchers the freedom to choose the methods, techniques and procedures that best suit their needs and purposes.

Building on constructivism, Lev Vygotsky's theory of the 'zone of proximal development' suggests that there is a gap between that which children can learn alone, and that which they can learn with assistance of an adult or a peer who is more knowledgeable or more experienced. Thus, children engaged in solving a mathematical problem can have their learning moved forward by a timely suggestion or thoughtful question. Moreover, according to Vygotsky (1986), children develop language (the tool of thought) through a combination of cognitive constructivism, where understanding develops alongside maturation, and social constructivism where understanding develops specifically through social interactions. Drawing on Vygotsky's work, Egan (1997), argues that the development of language begins with external social interaction with others, and becomes internalized as the child matures. The culture in which children grow up, therefore, shapes their psychological makeup and will have a significant effect on the understanding that they construct of the world around them. Intellectual development could be said to be dependent on a person's ability to use tools such as language effectively in 
different learning settings. Vygotsky's theory became the template for Bruner's model (1976) who believed that when children start to learn new concepts, they need help from teachers and other adults in the form of active support, which takes them from the status of dependent learners to the one of independent or autonomous ones as they acquire new skills. For Bruner, scaffolding represents a reduction in the many choices children might face, so that they become focused only on acquiring the skill or knowledge that is required.

\section{Methodology}

The use of a mixed-method-design study provided a more complete understanding of the research questions as it combined quantitative and qualitative approaches which "minimizes the limitations of both approaches" (Creswell, 2014-p.218). For Gay (2012), the use of multiple methods, data collection strategies, and data sources or triangulation helps to get a complete picture of the topic under study and helps in cross- checking information. Therefore, this study had two phases. It involved, in phase one, an exploratory inventory, and in phase two interviews, questionnaires, and class observations.

\section{Study Population and Samples}

In the first phase, 273 private schools in North-Lebanon were invited to respond to an inventory about the use of active learning strategies (ALS); 339 teachers from all disciplines responded, of which 129 were math teachers. In the second phase, the sample was chosen from Tripoli, the capital of North Lebanon. The participants were purposefully selected from five out of seven English speaking schools that welcomed the study while two apologized. Thus, five Cycle Two coordinators and ten Mathematics teachers were involved in the study. For confidentiality purposes, the names of the schools, teachers and coordinators were coded as A, B, C, D and E. Teachers were then assigned a number preceded by the school alphabetical letter.

\section{Instruments}

Four instruments were used to answer the research questions: (1) a 14item inventory in English and Arabic to explore the familiarity of teachers and their use of active learning strategies and teaching practices; (2) an interview composed of 6 questions meant to understand Cycle Two Mathematics coordinators' perceptions about teaching practices and students' achievement in problem solving; (3) a questionnaire for teachers to identify the difficulties encountered in teaching and learning and how to solve Mathematics problems; it consisted of 10 multiple choice questions, and one open ended item that was analyzed qualitatively, and (4) a class observation grid to verify the use of ALS in classes, adapted from Moukarzel (2011). 
Instruments were piloted for content validity. The questionnaire was also reviewed by experts in the field to certify its reliability. Authorization from the Center of Ethics at Saint-Joseph University of Beirut was obtained before proceeding with the study.

\section{Procedures}

The inventory was sent to school principals in North Lebanon who asked teachers to complete them using a specific online link in order to secure confidentiality. Then, letters explaining the objectives of the study were sent to the seven private schools in Tripoli that were found using English as a means of instruction asking them permission to: (a) interview the Mathematics coordinators to clarify how teaching problem solving was taking place, and what could be challenging students' learning, (b) request Cycle Two Mathematics teachers to complete a questionnaire about their familiarity with ALS in teaching problem solving and their perceptions about students' skills in solving Mathematics problems, and (c) observe Mathematics classes and make notes of the teaching and learning process.

\section{Results} questions.

Data was collected to help the researchers answer the research

\section{A-The inventory:}

\section{a- Profile of participants}

Three hundred thirty- nine (339) teachers responded to the 14-item inventory in the area of North Lebanon, of which 270 females (79.64\%) and 69 males $(20.35 \%)$. Out of the 339 responses, 129 were Mathematics teachers (38\%), of which 95 were female $(73.6 \%)$ and 34 were male $(26.4 \%)$ (Figure 1).

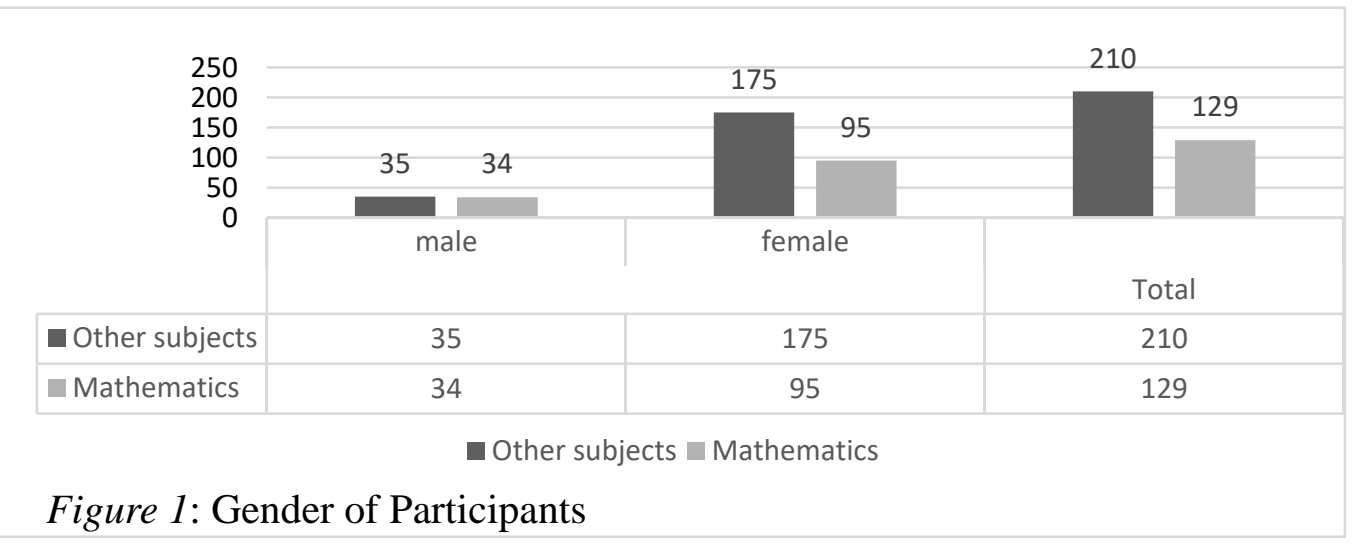


Regarding participants' highest degrees, 171 out of the 339 affirmed having a Bachelor degree (50.44\%) and 124 a Master's degree (36.57\%) (Figure 2).

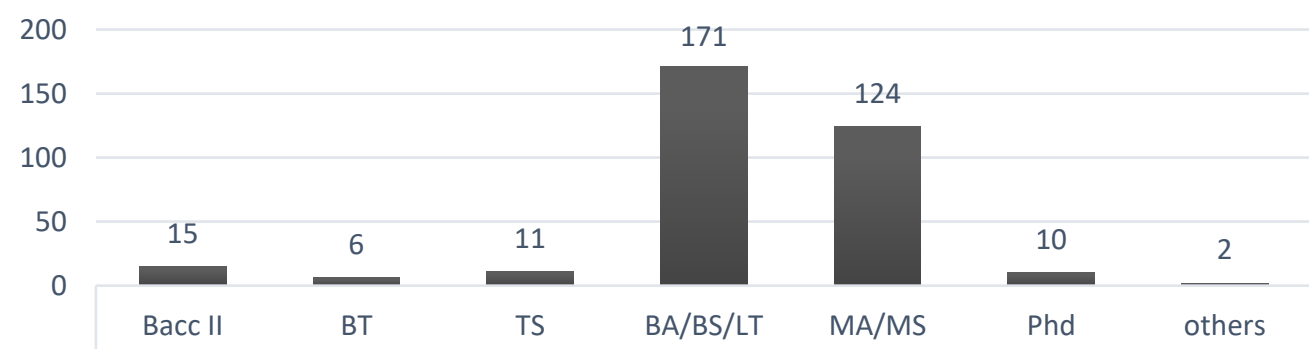

Figure 2: Participants' Highest Degree Degrees $^{\text {. }}$

b- Active learning usage by Mathematics teachers:

Out of the 129 Mathematics teachers, 126 affirmed implementing ALS in class (97.67\%) (Figure 3).

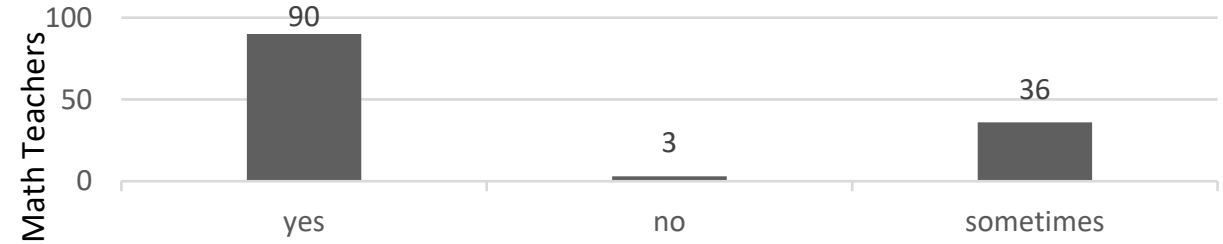

Figure 3: Teachers' Use of Active Learning Strategies

The highest percentage of ALS usage was for group work $(n=101$; $78.29 \%)$, followed by Think/Pair/Share (TPS) $(n=87 ; 67.44 \%)$, then by inquiry-based learning (IBL) $(n=67 ; 51.93 \%)$. Finally, 36 teachers affirmed using Socratic Questioning (SQ) (27.9\%), while 25 applied the lecturing method (19.37\%) (Table 1).

Table 1

Strategies Used in Teaching Mathematics

\begin{tabular}{ccc}
\hline Strategy & Number of Teachers & Percentage of Teachers \\
\hline Inquiry Based Learning & 67 & $51.93 \%$ \\
Group Work & 101 & $78.29 \%$ \\
Think/ Pair/Share & 87 & $67.44 \%$ \\
Lecturing & 25 & $19.37 \%$ \\
Socratic Questioning & 36 & $27.9 \%$ \\
\hline
\end{tabular}


When asked about ALS implementation at different times during a lesson, teachers' responses varied as they could choose more than one answer: 76 affirmed using ALS for warm-up activities (58.91\%), 83 during a lesson (64.34\%), and 65 when needed (50.38\%) (Table 2).

Table 2

Timing of implementing ALS

\begin{tabular}{ccc}
\hline Timing & Number of teachers & Percentage \\
\hline During Warm Up Activities & 76 & $58.91 \%$ \\
During the Lesson & 83 & $64.34 \%$ \\
At the End of a Lesson & 20 & $15.5 \%$ \\
When Needed & 65 & $50.38 \%$ \\
I Don't know what AL is & 1 & $0.77 \%$ \\
\hline
\end{tabular}

The rationale chosen for using AL seemed to be obvious to most of the teachers who responded: 122 said it enhances student learning, 120 said it guarantees their involvement, and 116 believed it raises their communication skills (Figure 4).

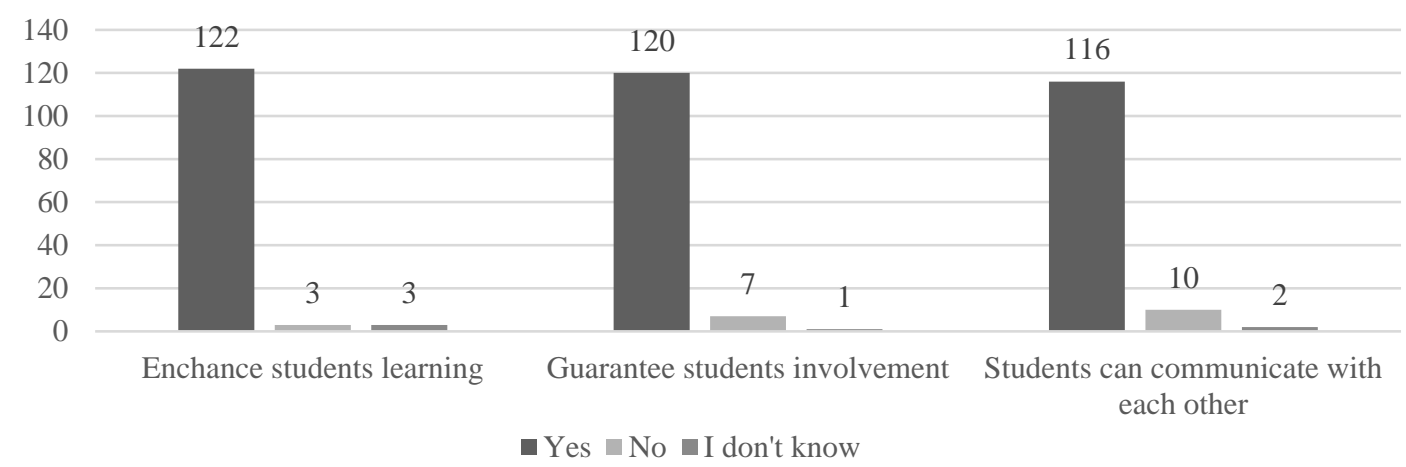

Figure 4: Rationale for Using ALS

This preliminary exploration showed that most of Mathematics teachers affirmed using, in a way or another, more than one active learning strategy and at different times during their teaching.

\section{B. The interviews with Mathematics coordinators}

The five mathematics coordinators were females at Cycle Two; 4 out of the 5 had over 7 years of experience in their position while one of them was recently appointed. The interviews took place in their offices at schools. Only two coordinators accepted to record the interviews which were transcribed later. During the three other interviews, hand notes were taken. 
There were six questions directly related to their perceptions of students' difficulties in problem solving (PS). All transcriptions were coded and categorized, and three main themes emerged: language, implementation of active learning strategies, and students' analytical skills.

Out of the 5 coordinators, 4 affirmed that teachers use ALS in Mathematics teaching while the remaining one considered "students' autoevaluation" as the only means used as active learning strategy without further explanations. Regarding the "tangibles" (a word used in the interview) such as blocks, counters, fraction bars and the like, only three out of the five coordinators seemed acquainted with these means of learning while the two others were relying on textbooks and workbooks. For example, School A coordinator said that using tangibles "is our daily bread" whereas School C coordinator said clearly" they are very limited at our school".

Despite the explanations aforementioned, all coordinators stated that students still did not enjoy solving Mathematics problems, but 4 out of the 5 stated that they enjoy group work, which was considered by the fifth coordinator in school B as an "opportunity for them to waste time". Reasons for not enjoying PS were different from one school to another. In school C, the coordinator believed that "students do not want to read the problems" they had to solve; in School D, the answer was that "the older the students get, the bigger the problem becomes because they don't want to learn, they are not enthusiastic, and they don't have a goal." However, in school A, the coordinator stated that "students enjoy solving problems when they act them out".

On the other hand, all coordinators believed that the factor of language was a barrier for students to solve word problems, especially in Grade Four. This was considered as a challenge in problem solving since it was not only about understanding the problems but also about expressing their ideas in English. School C coordinator stated "students want to solve problems quickly and they don't want to write". School A Coordinator could summarize thoughts when saying "the main challenge is to teach them how to analyze a problem", and for that, school C coordinator elaborated in her comments "they just want to give the answers; they don't know how to write it in steps to show how they analyze". For school E, the difficulty for students was "to choose the right operations to perform."

Hence, teaching students how to break down problems and build their analytical skills were considered the main challenges faced by teachers.

Based on the above, it was clear from the interviews that English, a foreign language for Lebanese students, was a barrier in understanding word problems, some of the coordinators lacked knowledge about active learning strategies or their implementations, and students were unable to analyze problems in order to solve them. 


\section{Teachers' Questionnaires}

a- Profile of respondents

Ten teachers completed anonymously a 10-item questionnaire. The majority at Cycle Two were females (90\%). Seven out of ten had a BA degree, two had a MA/MS, and one female teacher had an engineering degree (Table $3)$.

Table 3

Teachers Degrees

\begin{tabular}{ccc}
\hline Degrees Earned & $n$ & $\%$ \\
\hline BA & 7 & $70 \%$ \\
MA & 2 & $20 \%$ \\
Engineering & 1 & $1 \%$ \\
\hline Total & 10 & $100 \%$ \\
\hline
\end{tabular}

b- Active learning usage by Mathematics teachers:

All respondents affirmed attending training in ALS, and nine out of 10 stated that they implemented these strategies in class: 60\% used ALS in every session, $20 \%$ used them at the beginning of a unit or lesson, $10 \%$ once per month, while $10 \%$ said "never" (Table 4).

Table 4

The Use of ALS by Math teachers in Cycle Two

\begin{tabular}{ccc}
\hline Usage & $\begin{array}{c}\text { Number of } \\
\text { Teachers }\end{array}$ & Percentage \\
\hline Every session & 6 & $60 \%$ \\
Once per month & 1 & $10 \%$ \\
At the beginning of the unit & 2 & $20 \%$ \\
Never & 1 & $10 \%$ \\
Total & 10 & $100 \%$ \\
\hline
\end{tabular}

Regarding the strategies used: 7 teachers said that they use group work and brainstorming, 6 teachers affirmed using questioning, and Think/Pair/Share (TPS), 5 teachers use inquiry-based learning. For the jigsaw strategy, it was chosen by the only teacher who said previously that he was not using ALS (Figure 5). 


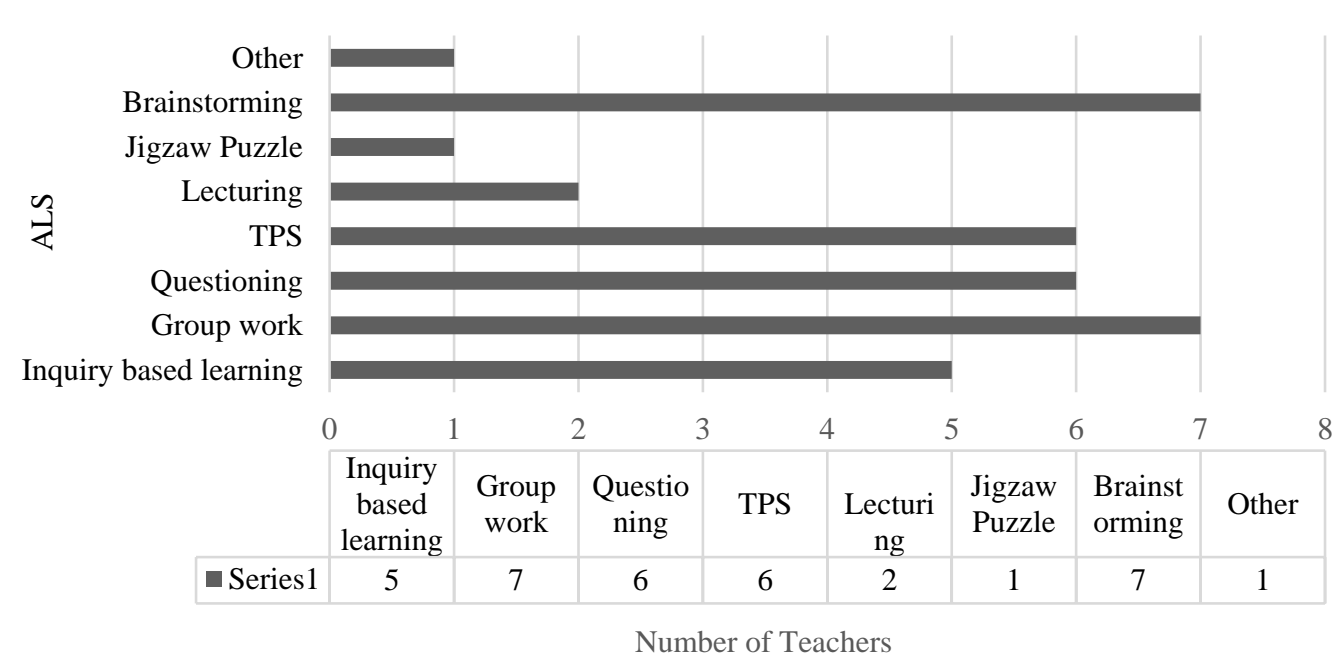

Figure 5: Active Learning Strategies Used by Teachers

c- Students difficulties in problem solving:

Nine teachers out of the $10(90 \%)$ claimed that "some" of their students were struggling with PS, while one teacher said that this was the case of all students "in general". Three main reasons were proposed to choose from, with an open-ended section under "other reason". Almost all teachers (90\%) admitted that language was the main reason behind students' struggles in PS (Table 5), while $80 \%$ believed that students lacked the ability to think critically, yet none pointed out to the lack of motivation among their students. One teacher wrote that students "look for keywords only" (Table 5).

Table 5

Reasons for Students' Struggle in Problem Solving

Causes Number of times identified by Percentage teachers

a-Language issue

9

$90 \%$

b- Critical thinking issue

c-Lack of motivation

8

0

$80 \%$

d-Other reasons / Specify:

They look for keywords only

$0 \%$

$10 \%$

d- Teachers' suggestions:

In the open-ended part of the questionnaire, teachers were invited to give their suggestions to improve students skills in PS. Responses were coded and categorized. Three themes emerged, two of them similar to responses from the coordinators' interviews: language issue and students' lack of analytical skills. Across all responses, the third theme appeared as teacher's need 'for 
training in teaching PS", to "link it to real life situations", or "provide online games to raise students' interest".

\section{Class Observations}

Fifteen class observations were conducted, one section of each grade level in Cycle (Grades 4-5-6), two in each of the five schools. The Mathematics coordinators attended class observations in two schools and completed the same checklists. The researchers then compared the results, which were similar; this ascertained the reliability of the instrument.

From the class observations, two themes emerged: the language used during instruction and the methods of teaching.

a- Language used during instruction:

Based on the observations, in 10 out of the 15 classes attended (66\%), teachers had good command of the English language, using it properly mostly in schools A, B and E. The students also answered in English and showed no difficulty in understanding the language (Figure 6).

In Schools C and D, some of the teachers used Arabic with English keywords, and students responded in the same way.

b- The usage of ALS:

Regarding the teaching strategies, some teachers used ALS within the warm-up activities. For instance, in School A (Gr.4 and Gr.6), and in school B (Gr.4), teachers started their lesson with warm-up activities like discussing a topic after watching a short video. Teachers in School D (Gr.4) and School E (Gr.6) started their session by asking questions about the previous lesson and eliciting answers from students throughout the class. However, in all the other classes, teachers began by correcting the homework (66.6\%).

On the other hand, in the course of each session observed, the researchers did not see much of ALS implementation. ALS appeared only in School A in Gr.5 and Gr.6 (13.3\%). The teachers engaged the students in group work to explain the topic and solve word problems. Although in six classes out of the $15(40 \%)$ the teachers asked the students to work in pairs to find solutions, the researchers noticed that students were not given ample time to read the problems, nor to reflect alone or with their partners before requesting their answers.

As for the wrap-up at the end of the observed sessions, teachers in six classes School A (Gr.6), School B (Gr.6), School C (Gr.4, Gr.5, Gr.6), and School D (Gr.4) (40\%) ended the class period by summarizing the important points acquired in the lesson. The other sections either ended by giving an assignment, or were force-stopped by the ringing bell sound. None of the 
classes observed went beyond the "application level" of Bloom's Taxonomy (Anderson, 2001).

By the end of the 15 class observations, the researchers realized that group work and ALS were well implemented only in school A where all students were on task the whole periods observed. In the 4 other schools, instructions were teachers' centered with slight use of teaching aids or manipulatives.

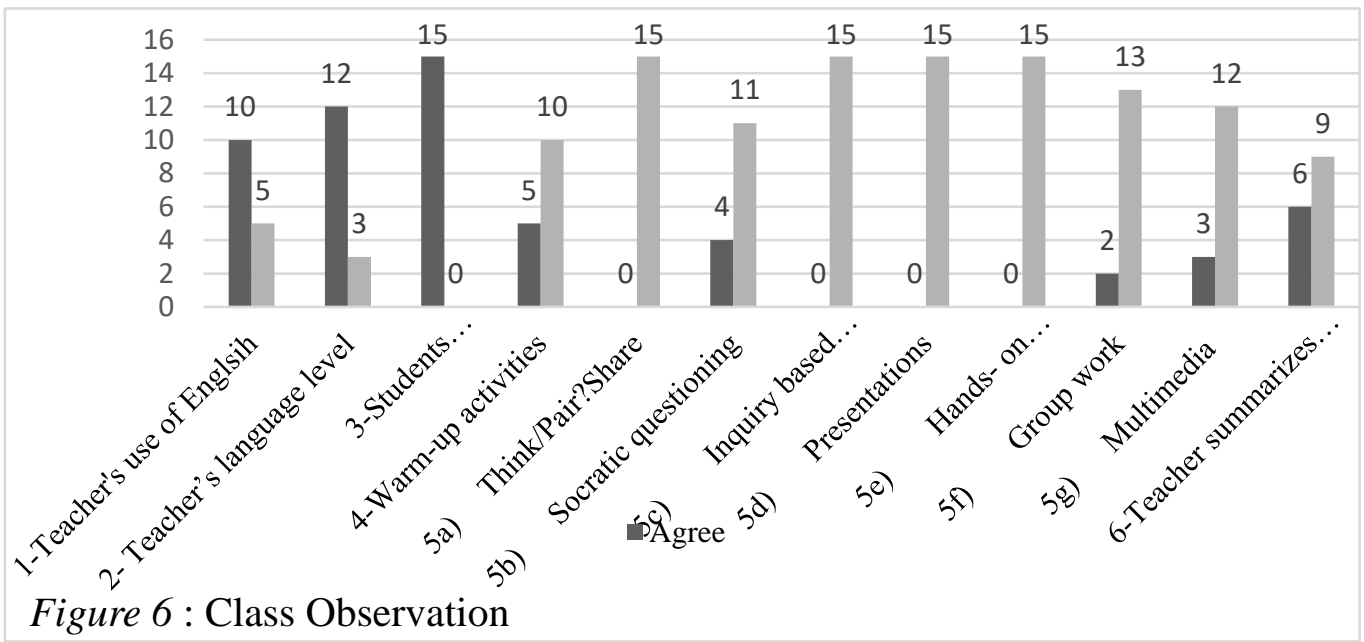

\section{Discussion}

To answer the first research question "What are the instructional methods used in teaching problem solving in Tripoli's private schools?" responses from the inventory and teachers questionnaires (TQ) were compared. They showed similar percentages in the use of ALS in general (90\%), which dropped to about $(60 \%)$ in both instruments when it came to daily usage. Class visits revealed that ALS was used only in 2 classes out the $15(13.3 \%)$ though teachers were aware of the researchers' aim to observe problem solving teaching methodologies. This contradicted Kolb's Learning Cycles (2014) and Schoolcraft (2015) who recommend to start with a concrete experience and continue with reflection and modification, thus alternating reflection and discussion.

On the other hand, though teachers claimed using group work, IBL and TPS, class observations showed poor application of group or pair work while IBL was not observed at all. Mostly, teaching practices were based on asking questions and eliciting answers with individual students, which contradicted teachers' claim about using ALS in $60 \%$ of their sessions. It brought students to becoming passive learners who waited for others to give the answers as revealed in school D interview, which was raised in studies by Kagan (2001) 
and Fisher (2002). Al-Alloul (2012) also concluded in her study that there was a significant difference at $(a \leq 0.05)$ between pre and post Mathematics solving problems scores when applying active learning strategies for the experimental group on developing Mathematics solving problems skills.

To answer the second research question "What are the Mathematics teachers' and coordinators' perceptions about students' difficulties in problem solving in Cycle Two?" responses from the coordinators' interviews and teachers' questionnaires highlighted the role of language as a barrier in students' understanding and students' difficulties in analyzing word problems. Class observations were consistent with their claims; teachers who used English all the time in class, received full responses in English from their students . On the other hand, teachers who did not have a good command of English, or used Arabic all the time, decreased the chance for their students to listen, learn and acquire the language of mathematics in English as recommended by Schoolcraft (2015). As for students' ability to analyze, it was not observed because teachers chose activities with specific questions at the "understanding and application levels" if we refer to Bloom's Taxonomy. Moreover, during teacher-student or student-student interactions, when these happened, questions were also addressed at the low level of the taxonomy and few students were able to answer.

\section{Conclusion}

This exploratory study showed that teachers did not fully engage students in learning how to solve mathematic problems or in monitoring their own progress and understanding, which was inconsistent with the teachers' responses to the inventory and questionnaire. Teachers' and coordinators' responses showed that the majority of the students lacked the skills and motivation due to two main reasons: language barrier and poor analytical skills. The underlying reason could be the teachers and coordinators lack of knowledge on how to remedy these issues, and their need for specific training programs. Studies on the effects of in-service teacher training showed improvement in students' performance in Mathematics (Charalombos, 2010; Dennis, 2017); moreover, according to Moukarzel (2011),ongoing and continuous education ameliorate teachers' performance and students' participation.

\section{Recommendations}

Based on findings, areas for further research can be highlighted, mainly having teachers' training about (a) Essential active learning strategies for problem solving; (b) Language proficiency mainly for mathematic teachers; and (c) Coordination between the English and Math departments to improve students' levels in the use of English. On another level, it would be important 
to listen to students' concerns and seek their perceptions about mathematics, and specifically problem solving, to help them overcome their difficulties.

\section{References:}

1. Affana, E . \& Zaanin, J. (2001).Enriching Mathematics and Sciences. In Al-Alloul, R. (2012). The Effect of Using Some Active Learning Strategies to Develop Mathematical Problem Solving Skills for Grade Four Students in Gaza. (Published master's thesis). Al-Azhar University- Gaza

2. Anderson, L. W., \& Bloom, B. S. (2001). A taxonomy for learning, teaching, and assessing: A revision of bloom's taxonomy of educational objectives (Abridged.). New York: Longman.Bruner, J. (1986). Actual minds, possible worlds. Cambridge, MA: Harvard University Press.

3. Bandura, A. (1999). Social cognitive theory: An agentic prespective. Asian Journal of Social Psychology, 2, 21-41. Doi:10.1111/1467839X.00024

4. Bruner, J. and Haste, H. (1987). Making sense: the child's construction of the world. London, New York: Methuen.

5. Charalombos, Y.C. (2010). Mathematics Knowledge for teaching and Task Unfolding: An Exploratory Study, The Elementary School Journal, 110(3)

6. Claxton, G. (2008). What's the point of school? Rediscovering the heart of education. Oxford: One-world Publications.

7. Creswell, J. W. (2014). Research design: Qualitative, quantitative, and mixed methods approaches (4th ed.). Los Angeles: SAGE.

8. Dennis, N.,Wambua, K \& Peter, O. (2017). The effect of Smasse inservice training on performance of mathematics in selected secondary schools in Kenya. Europen Scientific Journal, 13,169-185. Doi:10.19044/esj.2017.v13n10p169.

URL:http://eujournal.org/index.php/esj/article/view/9150/8707;

9. Dewey, J. (1938). Experience and education. New York: Macmillan.

10. Egan, K. (1997). The Educated Mind: how cognitive tools shape our understanding. Chicago. IL: University of Chicago Press.

11. Farrajallah, Abed el Kareem. (2017). The impact of employing the (think - pair - share) strategy to gain some number sense skills and mathematical communication skills among fifth grade students . AnNajah University Journal for research :Humanities. Vol. 31, no. 9, September 2017. pp. 1627-1663

12. Fisher, J. (2002) Starting from the Child. Buckingham: Open University Press. 
13. Frank K Lester Jr. (2013). Thoughts about research on mathematical problem-solving instruction. The Mathematics Enthusiast, 10 ((1/2). 245.

14. Gay, L., Mills, G. \& Airasian, P. (2012). Educational research: competencies for analysis and applications. $10^{\text {th }}$ edition. USA: Pearson Education Inc.

15. Kagan, S. (2001). Kagan Structures for emotional Intelligence. Kagan Online Magazine, 4(4), 1.

16. Kahney, H (1993). Problem solving; Current issues. England: United Kingdom.

17. Kolb, D. A. (2014). Experiential learning: Experience as the source of learning and development Pearson FT Press.

18. Lebanese Official Newspaper (1997). Scopes and Objectives of the K12 Curricula. Decree\# 10227. Issue (26).

19. McVarish, J. (2008;2012;). Where's the wonder in elementary Mathematics?: Encouraging Mathematics reasoning in the classroom (illustrat ed.). New York: Routledge. doi:10.4324/9780203940037

20. Michael, J.(2006). Where's the evidence that active learning works? Advances in Physiology Education, 30 (4), 159-167.doi:10.1153.2006

21. Michael, J.A., \& Modell, H.I.(2003). Active learning in secondary and college science classrooms: A working model for helping the learner to learn. Mahwah, N.J: L. Erlbaum Associates. Doi: $10.4324 / 9781410609212$

22. Monk, J., \& Silman, C. (2013;2014;). Active learning in primary classrooms: A case study approach. New York; London;: Routledge. doi: $10.4324 / 9781315833484$

23. Moukarzel, D. M. (2011). La formation continue des enseignants des écoles indépendantes au Qatar - étude de cas. Doctoral dissertation presented at Haute-Alsace University, Doctoral School of Humanities, Interuniversity Laboratory of Educational Sciences and Communication. France.

24. Newell, A., \& Simon, H. A. (1972). Human problem solving. Englewood Cliffs: Prentice Hall.(page 72)

25. Nelson,C. (2006). Fostering critical thinking: Comments and conversations. The Center for Excellence in Learning and Teaching (CELT). Brockport, NY; The College at Brockport. State University of New York.

26. Piaget, J. (1926). The language and thought of the child. New York: Harcourt Brace.

27. Piaget, J., \& Inhelder, B. (1969). The psychology of the child. New York: Basic Books. 
28. Schoolcraft, N.K. (2015). Think-Pair-Share and language in the high school geometry classroom (Order No. 3738778). Available from ProQuest Dissertations \& Theses Global. Retrieved from https://search-proquestcom.ezproxy.aub.edu.lb/docview/1746694408?accountid=8555

29. Skinner, B. F. (1966). An operant analysis of problem solving. In B. Kleinmetz (Ed.), Problem solving: Research, method, and theory (pp. 225-257). New York: Wiley.

30. UNESCO (2002). The Support Program to the Lebanese Elementary Level. The Evaluation of Gaols, Structure and Lessons Distribution. Vol 3 \& 4 .

31. Vygotsky, L. (1986). Thought and language. Cambridge, MA: MIT Press.

32. Vygotsky, L. S. (1978). Mind in society: The development of higher psychological processes. Cambridge, MA: Harvard University Press.

33. Wray, D. (2006). From learning to teaching. In Arthur, J., Grainger, T. and Wray, D. Learning to Teach in The Primary School. Oxford: Routledge. 